\title{
Frictional Performance Correlations for Calcined Bauxite and Alternative Aggregates
}

\author{
Eslam Deef-Allah, Korrenn Broaddus, Magdy Abdelrahman
}

\begin{abstract}
Calcined Bauxite $(\mathrm{CB})$ is a common aggregate used in high friction surface treatment. Due to the high price of $\mathrm{CB}$, six aggregates were investigated as alternatives to $C B$. These aggregates were Steel Slag, Meramec River Aggregate, Rhyolite, Earthworks, and Potosi Dolomite. Correlations between the frictional performance of these aggregates were scrutinized using an aggregate image measurement system (AIMS), British pendulum (BP), and dynamic friction tester (DFT). Micro-Deval (MD) was utilized, and its results correlated with the frictional testing results. A stronger correlation was observed between the angularity and sphericity indices when compared with the correlation between the texture and sphericity indices or when compared with texture and angularity indices. Inverse correlations were found between the MD percentages and texture or angularity indices. No correlations were found between AIMS and BP or between AIMS and DFT results. A direct linear correlation was distinguished between DFT and BP results.
\end{abstract}

Index Terms-AIMS, British Pendulum, Calcined Bauxite, Dynamic Friction Tester, Micro-Deval.

\section{INTRODUCTION}

High friction surface treatment (HFST) was identified as a cost-effective safety treatment consisting of a polymer resin layer, which was used to bond the pavement with a maximum size of 3-4 mm of high friction aggregate. The most common aggregate used in HFST is Calcined Bauxite (CB) [1]-[7]. A resin binder, such as epoxy resin, polyester resin, polyurethane resin, acrylic resin, or methyl methacrylate, is spread over the pavement surface to bond it to the layer of aggregate [1], [2], [4]. The most common resin binder used in the HFST is an epoxy resin that is a two-part binder that consisting of a resin (extender) and an epoxy (hardener) [4], [8].

Heitzman et al. [9] investigated the friction performances of seven friction aggregates and compared them with CB. None of the seven friction aggregates showed friction comparable to the $\mathrm{CB}$ based on the dynamic friction tester (DFT) results. Dynamic friction tester was utilized to measure the pavement surface frictions [9], [10] that provided estimations for the microtextures [11]. The

Eslam Deef-Allah, Ph.D. Candidate, Department of Civil, Architectural, and Environmental Engineering, Missouri University of Science and Technology, Rolla, MO 65409, U.S.A

Korrenn Broaddus, Ph.D. Student, Department of Civil, Architectural, and Environmental Engineering, Missouri University of Science and Technology, Rolla, MO 65409, U.S.A.

Magdy Abdelrahman, Ph.D., Missouri Asphalt Pavement Association (MAPA) Endowed Professor, Department of Civil, Architectural, and Environmental Engineering, Missouri University of Science and Technology, Rolla, MO 65409, U.S.A. researchers concluded that the friction aggregates had similar friction losses between $70 \mathrm{k}$ and $140 \mathrm{k}$ cycles. The circular texture machine (CTM) was used to evaluate the macrotexture by providing a mean profile depth (MPD) [9], [10]. No correlation was recorded between the DFT and CTM measurements. No correlations were found between the friction number, measured by the DFT, and angularity indices measured by the aggregate image measurement system (AIMS) [9]. The angularity indices reflected the sharpness of the aggregates' corners [9]. Heitzman and Moore [10] investigated the long-term friction loss trends (terminal friction) for eleven types of aggregates ( $\mathrm{CB}$ and ten alternatives). This was achieved by measuring the surface texture using CTM and DFT. The surface friction and MPD values were measured for the aggregate before and after polishing with the NCAT three-wheel polishing device (TWPD). There were no correlations found between the CTM and DFT results. Calcined Bauxite had the highest friction number compared to other aggregates [10].

Wilson and Mukhopadhyay [4] investigated the friction performances of two CB aggregate sources, one from China and the other from India, and a third unknown aggregate obtained from the United Kingdom (U.K.). The two CB aggregates showed the lowest mass loss (5.5\% average) after 50 minutes of polishing in Micro-Deval (MD), and the aggregate obtained from the U.K. yielded a higher mass loss (24.6\%). Calcined Bauxite aggregates showed the highest surface friction and MPD values. The aggregate obtained from the U.K. started with lower initial surface friction compared to the $\mathrm{CB}$ aggregates, and it polished faster than the CB aggregates. Furthermore, the U.K. aggregate showed lower MPD than the CB aggregates [4].

Mahmoud [12] showed that implementing a fitting curve at three MD polishing times- 0,105 , and 180 minutes - was sufficient to obtain the AIMS texture and angularity parameters instead of using fitting at nine polishing times. Aldagari et al. [13] used equations to predict the texture and angularity parameters using two points at 0 - and 105 -minutes polishing times, which was standard practice at the Texas Department of Transportation. However, fitting curves using three points - 0,105 , and 180 minutes - could be conducted if the 180-minutes polishing time was implemented. At 105-minutes of MD polishing, the rates of texture and angularity losses reduced significantly. Therefore, the 105-minutes time was considered the initial time when the aggregates approached the terminal values [13], [14].

The main objective of this research was to explore the correlations between the frictional performance properties of $\mathrm{CB}$ and alternatives. The frictional performance properties 
were texture, angularity, and sphericity indices using AIMS, the British pendulum number (BPN) values using the British pendulum (BP) test, and the coefficient of friction (COF) values using the DFT. The correlations between MD mass losses and AIMS texture or angularity indices were explored. The correlations between MD polishing times and AIMS texture, angularity, or sphericity indices were investigated. The AIMS texture and angularity indices were compared to the BPN values, and the AIMS texture or angularity indices were compared to the COF values measured by the DFT. Additionally, the BPN values were compared to the $\mathrm{COF}$ values measured by the DFT.

\section{MATERIALS AND MeTHODS}

\section{A. Materials}

Calcined Bauxite and six alternatives were selected for testing. These aggregates were selected as possible alternatives to $\mathrm{CB}$. The alternatives were Meramec River Aggregate, Flint Chat, Earthworks, Rhyolite, Steel Slag, and Potosi Dolomite. A two-component (A and B) low modulus epoxy polymer binder-FasTrac CE330 epoxy binder-was utilized to prepare the coupons and HFST applications on hot mix asphalt (HMA) slabs.

\section{B. Methods}

\section{B.1. Micro-Deval}

The aggregates were tested for their degradation/polish resistances in the MD apparatus. The MD test was utilized to explore aggregates' durability and resistances to polishing, abrasion, and grinding in the existence of water [4], [11], [15]. The coarse aggregate MD tests were run following ASTM D6928 - 17 [16] on aggregate sizes passed from the sieve $3 / 8^{\prime \prime}$ and retained on \#4 (3/8" - \#4). The test was run for 105 and 180 minutes. Each aggregate had one sample tested for each run time.

\section{B.2. Aggregate Image Measurement System}

After the samples were tested using the MD test (105- and 180 -minute abrasion times), they were tested in the AIMS with aggregate samples before MD abrasion. Two sizes (3/8" - 1/4" and 1/4" - \#4) for each aggregate were explored using AIMS. The AIMS analysis was conducted to explore the changes that occurred to the aggregates' shapes (texture, angularity, and sphericity indices) after MD abrasion. The gradient angularity $(G A)$ is the sharpness of the corners of two-dimensional images of aggregate particles, and it was calculated from Eq. (1) [17]. The relative scale of angularity is from 0 to 10000; the prefect circle has an angularity value of 0 . The texture $(T X)$ is the relative roughness or smoothness of surface features less than $0.5 \mathrm{~mm}$ in size. The texture was estimated using Eq. (2) [17]. The relative scale of texture ranges from 0 to 1000 ; the smooth polished surface has a value of 0 . Sphericity $(S P)$ is the shape of the particle in three-dimension, and it was calculated using Eq. (3). It has a relative scale of 0 to 1 ; particle with equal dimensions (cubical) has a sphericity value of 1 [17]. Fig. 1 shows the difference between angularity, texture, and sphericity. The $G A$ is characterized by the following equation:
$G A=\frac{1}{\frac{n}{3}-1} \sum_{i=1}^{n-3}\left|\theta_{i}-\theta_{i+3}\right|$

where, $\theta$ is the angle of orientation of the edge points, $n$ is the total number of points on the edge of the particle, and $i$ is the $i^{\text {th }}$ point on the edge of the particle.

The $T X$ is represented by the following equation:

$T X=\frac{1}{3 N} \sum_{i=1}^{3} \sum_{j=1}^{N}\left[\boldsymbol{D}_{i, j}(x, y)\right]^{2}$

where $D$ is the decomposition function, $n$ is the decomposition level, $N$ is the total number of coefficients in an image, $i$ is 1,2 , or 3 for detailed images, $j$ is wavelet index, and $(x, y)$ is the location of the coefficients in the transformed domain.

The $S P$ is characterized by the following equation:

$S P=\sqrt[3]{\frac{d_{S} \times d_{I}}{d_{L}^{2}}}$

where $d_{s}$ is the particle shortest dimension, $d_{I}$ is the particle intermediate dimension, and $d_{L}$ is the particle longest dimension, note Fig. 1.

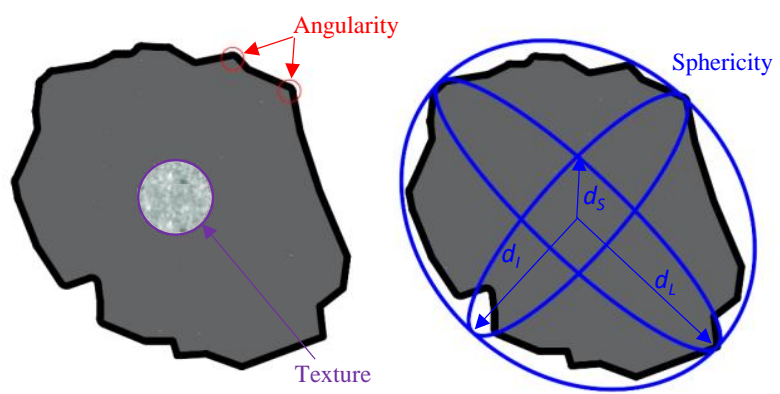

Figure 1. Aggregate's angularity, texture, and sphericity

\section{B.3. Accelerated Friction Testing}

\section{B.3.1. Preparing High Friction Surface Treatment Applications on Hot Mix Asphalt Slabs}

Loose asphalt mixtures were acquired from an asphalt plant in Pullman, WA, U.S.A. They were dense-graded asphalt mixtures with a $12.5-\mathrm{mm}$ nominal maximum aggregate size. The plant mixtures were reheated, and the HMA slabs (20-inch $\times 20$-inch $\times 2$-inch) were prepared and compacted in the laboratory using a small plate compactor. Two-component (A and B) epoxy binder was applied to the surface of the HMA slabs before the aggregates sized \#6 - \#8 were spread. The ratio of component A to component B of the epoxy was 1.18 to 1.00 by weight per the instructions from the supplier.

\section{B.3.2. Dynamic Friction Test}

A TWPD was used to polish the test slabs. The TWPD had three pneumatic rubber wheels attached to a turntable, and it had a water spray system to simulate wet conditions, thereby reducing the wear of the rubber wheels and washing away the fines at the surface allowing more polishing. The total weight on the wheel including the metal plates (total of six plates) and wheel cluster was $149 \mathrm{lb}$. The researchers measured the 
COF at different polishing cycle numbers [i.e., 0 cycles (initial), 70k cycles, and 140k cycles (terminal)]. The COF was measured using a DFT at different speeds (20, 40, and 60 $\mathrm{km} / \mathrm{hr}$ ) following ASTM E1911 - 19 [18]. The DFT consisted of a circular disk with three rubber pads attached to the disk. The circular disk rotated up to $100 \mathrm{~km} / \mathrm{hr}$. Once the disk reached the specified speed, the disk was lowered to the HFST surface, and the COF was measured as the speed of the rotating disk when it gradually decreased. The friction was measured in wet conditions. The results were based on the average of two replicates (two test slabs).

\section{B.4. Measuring Aggregate Coupons' Surface Friction Using the British Pendulum}

\section{B.4.1. Preparing Aggregate Coupons}

A ready-mix plaster with a weight of $12 \mathrm{~g}$ was added and spread on the bottom of the metal molds, and the aggregates were embedded into the plaster so that the plaster prevented the epoxy binder from flowing into the gaps between the aggregates' particles. The used aggregates were sized \#4 - \#6 and \#6 - \#8. Additional plaster was painted onto the sides of the molds using a small brush to completely cover the surface and keep the epoxy from adhering to the metal molds. A two-component (A and B) epoxy binder was prepared. The ratio of component $\mathrm{A}$ to component $\mathrm{B}$ of the epoxy was 1.18 to 1.00 by weight. The prepared epoxy binder was poured on the aggregates to fill the remaining space in the metal mold. The aggregate coupons were left in the metal molds at room temperature for 4 to 6 hours. Finally, the aggregate coupons were removed from the metal molds and washed with water to remove the plaster layers. The coupons made were tested for their initial BPN, run through the polishing process in the British wheel for 10 hours, and then tested for their BPN after 10-hours of polishing time.

\section{B.4.2. British Pendulum Test}

This test was run following AASHTO T 278-90 [19]. The test aimed to measure the surfaces' frictional properties using the BP. The tester was prepared according to the AASHTO T 278-90 [19] with zero adjustments (see Section 7.2) and slide length adjustments (see Section 7.3). A slider with dimensions of 1/4-inch $\times 1$-inch $\times 1$ 1/4-inch was used. Each coupon was tested 5 times. The BPN values were recorded on the F-scale as BPN values before polishing. Then, the aggregates on the coupons were polished using the British wheel, and the BPN values were recorded using the BP device after polishing (BPN values after polishing).

\section{B.4.3. Accelerated Polishing of Aggregates Using the British Wheel}

The aggregates on the coupons were polished-after they were tested in the BP-following AASHTO T 279-18 [20] using the British wheel. The test simulated the polishing action for aggregates in the field. For each run, 14 aggregate coupons were clamped around the periphery of the road wheel. The speed of the road wheel was set to $320 \pm 5 \mathrm{rpm}$, and the pneumatic-tired wheel was lowered to bear on the surface of the aggregate coupons with a total load of $391.44 \pm$ $4.45 \mathrm{~N}$. The aggregates were subjected to polishing action for 10 hours with the presence of water and polishing agent (\#150 silicon carbide grit).

\section{RESUltS AND ANALYSIS}

\section{A. Correlations between AIMS Results}

\section{A.1. Correlations between Texture and Angularity Indices}

Fig. 2 shows the correlations between average texture and average angularity indices before Micro-Deval abrasion (BMD), after 105-minutes abrasion time in Micro-Deval (AMD 105), and after 180-minutes abrasion time in Micro-Deval (AMD 180). The outliers were removed from the trendlines; these outliers were indicated with a light gray color. Direct linear correlations were observed between average texture and average angularity indices as follows: aggregates that had the highest texture indices showed the highest angularity indices. The average angularity indices decreased for all aggregates with AMD 105 and AMD 180, except for Flint Chat that presented an increase in the average angularity index using AMD 105. Earthworks showed the highest average texture and average angularity indices during $\mathrm{BMD}$, and Steel Slag presented the highest average texture and average angularity indices for AMD 105 and AMD 180. Meramec River Aggregate had the lowest average texture and average angularity indices for BMD; Potosi Dolomite had the lowest average texture and average angularity indices for AMD 105 and AMD 180. After MD abrasion, the average texture and average angularity indices decreased for four aggregates. Conversely, Steel Slag, CB, and Meramec River Aggregate showed increases in average texture indices for AMD 105. This texture index increase continued for AMD 180 with Meramec River Aggregate. 


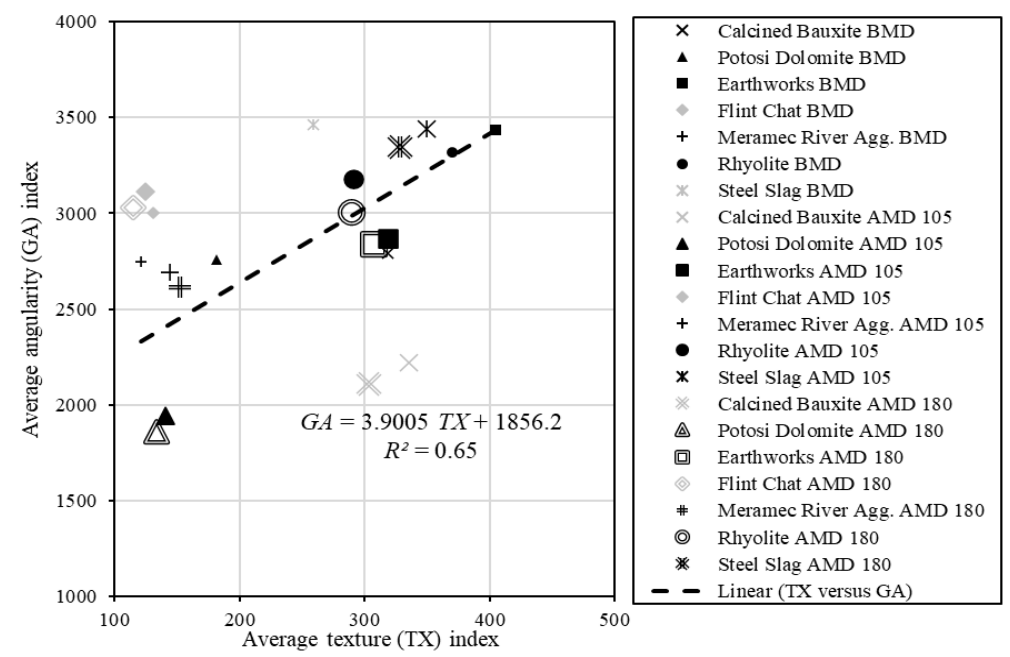

Figure 2. Correlation between average texture and average angularity indices

\section{A.2. Correlations between Texture and Sphericity Indices}

Fig. 3 demonstrates the correlations between average texture and average sphericity indices, including BMD, AMD 105, and AMD 180. The outliers were removed from the trendlines; these outliers were indicated with a light gray color. Exponential correlations were noted between average texture and average sphericity indices. Sphericity indices showed mixed results with MD abrasion. Sphericity indices for Steel Slag and Rhyolite decreased with MD abrasions. Sphericity indices increased with MD abrasion for Earthworks. Sphericity indices decreased AMD 105 and increased AMD 180 for CB and Potosi Dolomite. Flint Chat and Meramec River Aggregate had increased in sphericity indices for AMD 105; however, sphericity indices decreased for AMD 180.

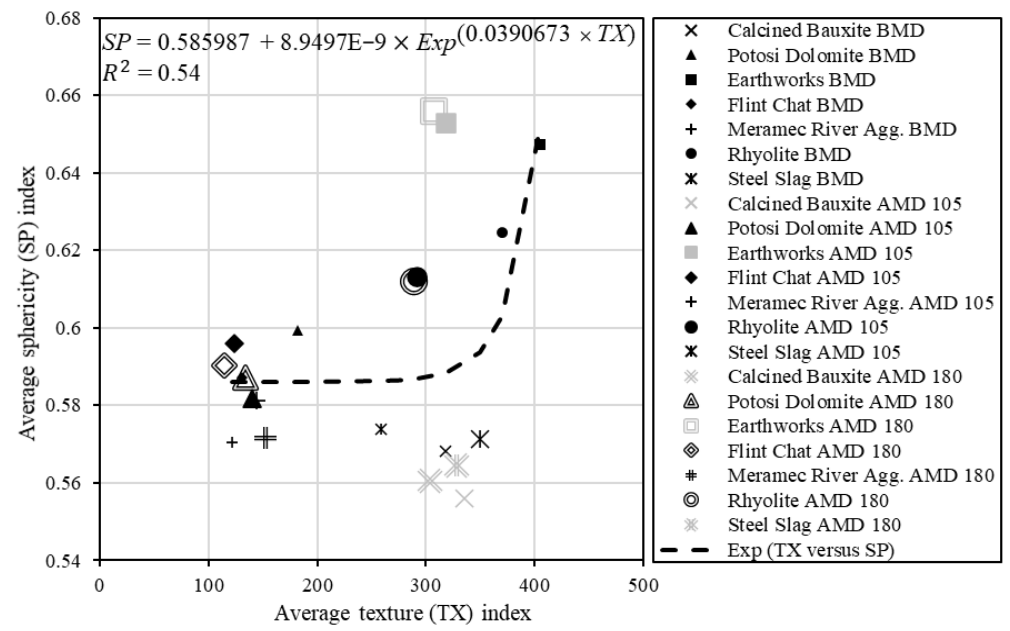

Figure 3. Correlation between average texture and average sphericity indices

\section{A.3. Correlations between Sphericity and Angularity \\ Indices}

Fig. 4 depicts the correlations between average angularity and average sphericity indices, including BMD, AMD 105, and AMD 180. The outliers were removed from the trendlines; these outliers were indicated with a light gray color. Exponential correlations were observed between average angularity and average sphericity indices. A stronger correlation was observed between the angularity and sphericity indices (Fig. 4) when compared with the correlation between the texture and sphericity indices (Fig. 3) or when compared with texture and angularity indices (Fig. 2). 


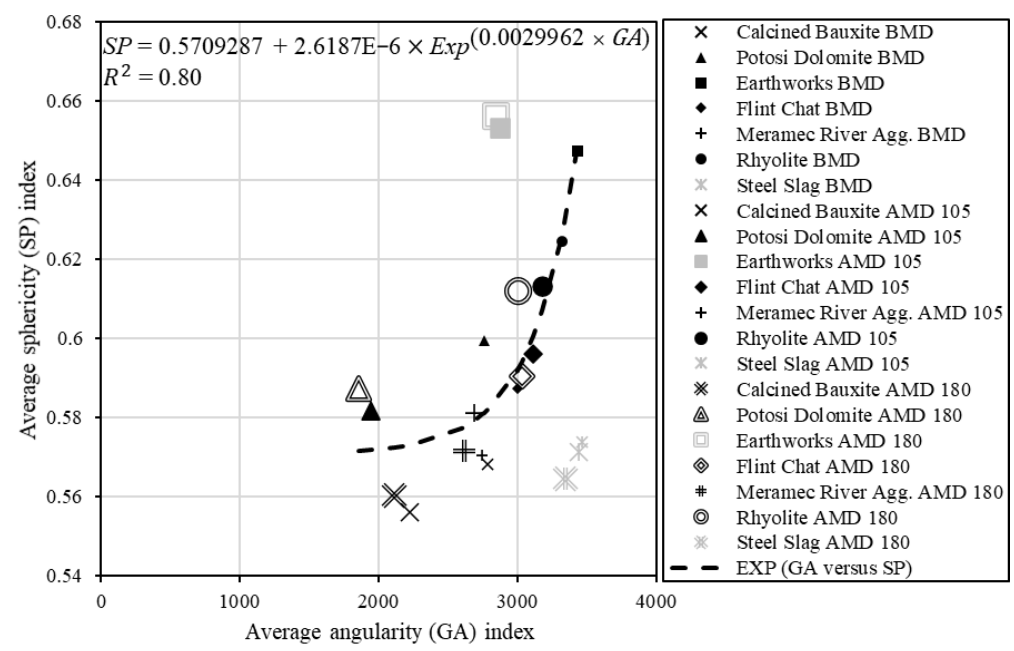

Figure 4. Correlation between average angularity and average sphericity indices

\section{B. Correlations between Micro-Deval and AIMS Results}

\section{B.1. Correlations between Micro-Deval Mass Losses and} Texture or Angularity Indices

The correlation between the percentages of MD mass losses and the average texture indices for AMD 105 and AMD 180 is shown in Fig. 5. The correlation between the percentages of MD mass losses and the average angularity indices for AMD 105 and AMD 180 is presented in Fig. 6. The MD test was conducted on aggregates with $3 / 8^{\prime \prime}-\# 4$ gradation. AIMS texture indices and AIMS angularity indices were calculated based on the results of two sizes $\left(3 / 8^{\prime \prime}-1 / 4^{\prime \prime}\right.$ and 1/4" - \#4). The outliers were removed from the trendlines, and they were indicated with a light gray color. Inverse correlations were found between the MD percentages of mass losses and average texture or angularity indices. Aggregate with the highest mass loss AMD — Potosi Dolomite - showed the lowest texture and angularity indices. Both figures show models that correlated MD mass losses and AIMS texture or angularity indices. Eq. (4) depicts the correlations between MD mass losses and the texture indices for aggregates used in the HFST application. However, Eq. (5) correlates MD mass losses and angularity indices for aggregates used in the HFST application. The predicted versus the measured texture indices are illustrated in Fig. 7. The predicted versus the measured angularity indices are shown in Fig. 8.

$T X=a \times M D_{\text {Loss }}+b$

where $T X$ is the texture index, $a$ and $b$ are the fitting parameters $(a=-11.918$ and $b=383.13)$, and $M D_{\text {Loss }}$ is the mass loss percentage of the aggregates after abrasion in Micro-Deval.

$G A=a \times M D_{\text {Loss }}+b$

where, $G A$ is the angularity index, and $a$ and $b$ are the fitting parameters $(a=-57.17$ and $b=3138.8)$.

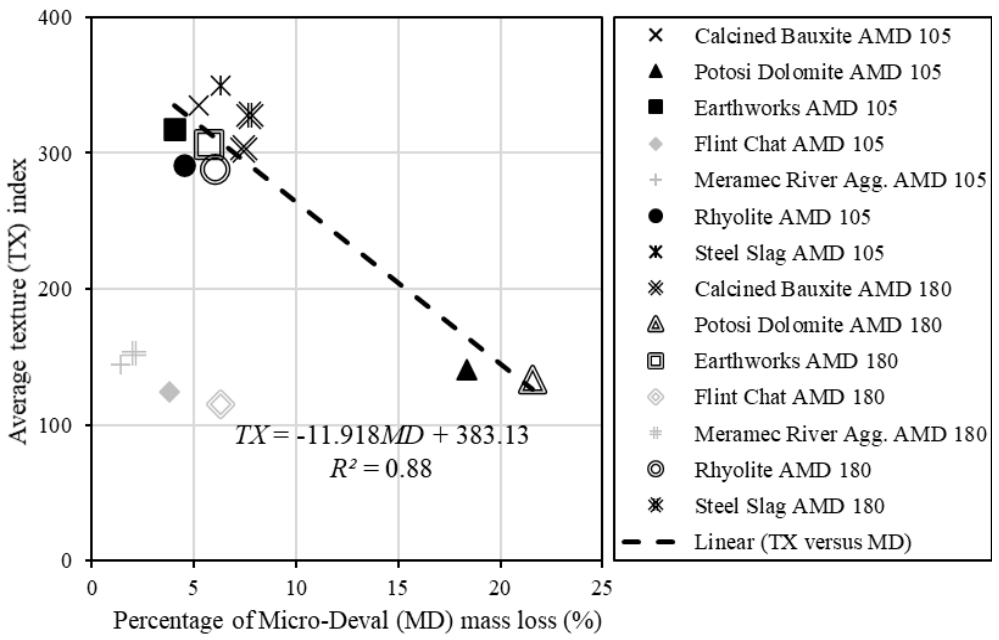

Figure 5. Correlations between Micro-Deval percentages of mass losses and average texture indices 


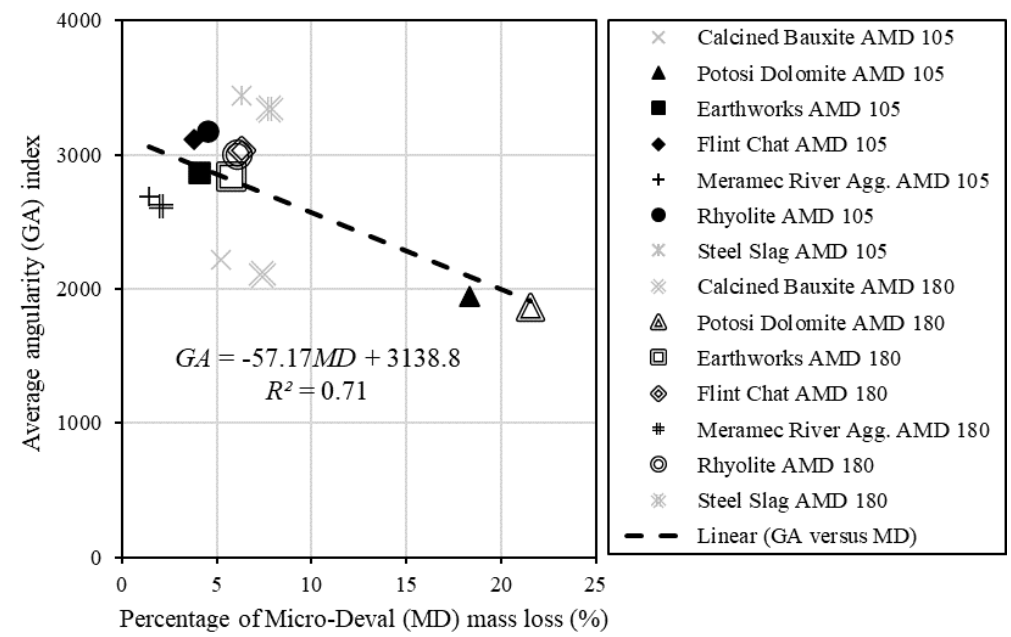

Figure 6. Correlations between Micro-Deval percentages of mass losses and average angularity indices

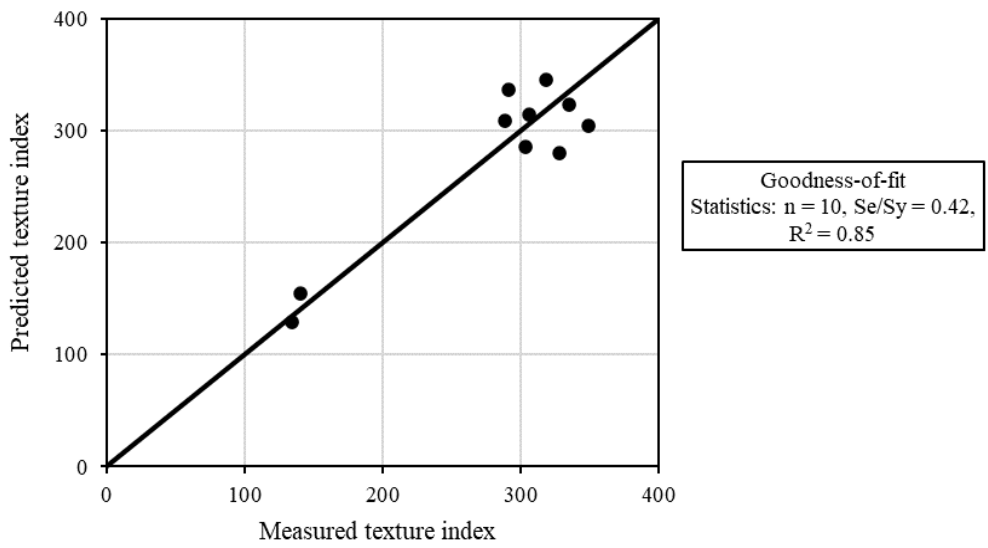

Figure 7. Predicted versus measured texture indices

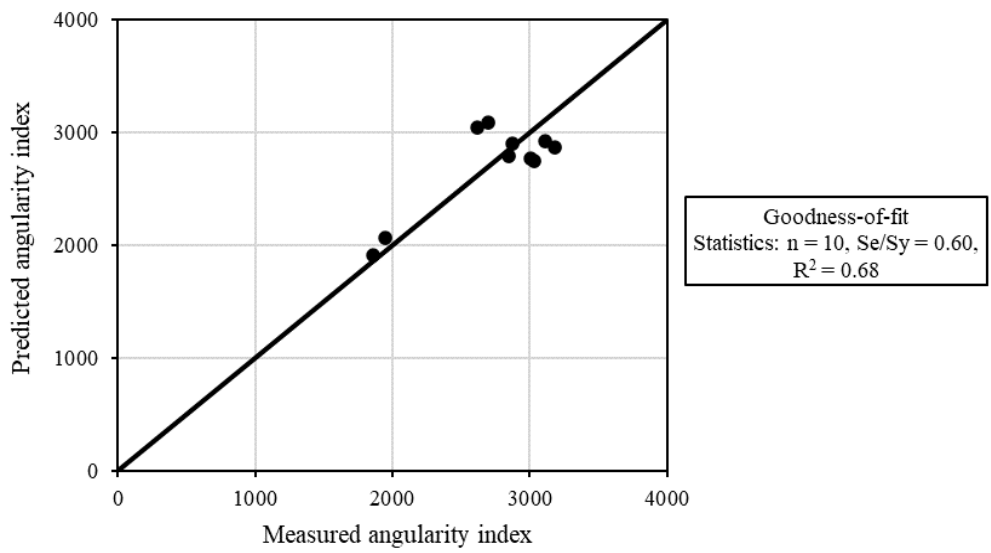

Figure 8. Predicted versus measured angularity indices

\section{B.2. Correlations between Micro-Deval Abrasion Times} and Texture, Angularity, or Sphericity Indices

The correlations between the texture indices and MD abrasion times for aggregates are illustrated in Eq. (6). The fitting parameters and the estimated sum of squared error (SSE) for the (TX-MD t) model are presented in Table 1.

$$
T X=a_{T X}+b_{T X} \times \operatorname{Exp}^{\left(-c_{T X} \times t\right)}
$$

where $T X$ is the texture index, $t$ is the Micro-Deval abrasion time, $a_{T X}$ is the terminal texture index. It should be greater than or equal to zero, $\left(a_{T X}+b_{T X}\right)$ is the initial texture index, and $c_{T X}$ is the rate of texture change.
The correlations between the angularity indices and MD abrasion times for aggregates are illustrated in Eq. (7). The fitting parameters and the estimated SSE for the (GA-MD t) model using are shown in Table 2.

$$
G A=a_{G A}+b_{G A} \times \operatorname{Exp}^{\left(-c_{G A} \times t\right)}
$$

where $G A$ is the angularity index, $t$ is the Micro-Deval abrasion time, $a_{G A}$ is the terminal angularity index. It should be greater than or equal to zero, $\left(a_{G A}+b_{G A}\right)$ is the initial angularity index, and $c_{G A}$ is the rate of angularity change.

The correlations between the sphericity indices and MD abrasion times for aggregates are depicted in Eq. (8). The fitting parameters and the estimated SSE for the (SP-MD t) 
model using are presented in Table 3.

$S P=a_{S P}+b_{S P} \times \operatorname{Exp}^{\left(-c_{S P} \times t\right)}$

where $S P$ is the sphericity index, $t$ is the Micro-Deval abrasion time, $a_{S P}$ is the terminal sphericity index, $\left(a_{S P}+b_{S P}\right)$ is the initial sphericity index, and $c_{S P}$ is the rate of sphericity change.

\section{Correlations between AIMS and BP Results}

Average AIMS texture and angularity indices for $3 / 8^{\prime \prime}$ 1/4" and 1/4" - \#4 aggregate sizes were compared with average BPN values for \#4 - \#6 and \#6 - \#8 aggregate sizes. Fig. 9 shows average BPN and AIMS results for aggregates. Average pre-polish BPN values were compared with average AIMS texture and angularity indices BMD (see Fig. 8a and Fig. 8b). Furthermore, average post-polish BPN values were compared with average AIMS texture and angularity indices for AMD 180 (Fig. 8c and Fig. 8d). No specific trend was noted between AIMS and BP results. Potosi dolomite presented the highest BPN values before and after polishing; however, it showed the lowest angularity indices for BMD and AMD 180, the second-lowest texture index for AMD 180, and the third-lowest texture index for BMD. Furthermore, Potosi dolomite depicted the highest mass loss percentages for AMD 105 and AMD 180.

Table 1. Fitting parameters for (TX-MD t) model

\begin{tabular}{llll}
\hline Aggregate & Texture Model Fitting Parameters & SSE & $R^{2}$
\end{tabular}

\begin{tabular}{llllll} 
Type & $a_{T X}$ & $b_{T X}$ & $c_{T X}$ & \\
\hline Calcined & 326.750 & $-2.9 \mathrm{E}-105$ & $-1.35 \mathrm{E}+00$ & $1.43 \mathrm{E}+02$ & 0.72
\end{tabular}

\begin{tabular}{llllll}
\hline Bauxite (CB) & & & & & \\
\hline $\begin{array}{l}\text { Meramec } \\
\text { River Agg. }\end{array}$ & 164.275 & $-4.29 \mathrm{E}+01$ & $7.18 \mathrm{E}-03$ & $1.10 \mathrm{E}-20$ & 1.00 \\
\hline Flint Chat & 137.277 & $-5.98 \mathrm{E}+00$ & $-7.38 \mathrm{E}-03$ & $2.95 \mathrm{E}-26$ & 1.00 \\
\hline Earthwork & 302.445 & $1.02 \mathrm{E}+02$ & $1.79 \mathrm{E}-02$ & $1.23 \mathrm{E}-23$ & 1.00 \\
\hline Rhyolite & 288.475 & $8.17 \mathrm{E}+01$ & $3.27 \mathrm{E}-02$ & $6.79 \mathrm{E}-26$ & 1.00 \\
\hline Steel Slag & 338.650 & $-8.01 \mathrm{E}+01$ & $1.23 \mathrm{E}+00$ & $2.31 \mathrm{E}+02$ & 0.95 \\
\hline Potosi & 130.775 & $5.11 \mathrm{E}+01$ & $1.57 \mathrm{E}-02$ & $8.08 \mathrm{E}-28$ & 1.00 \\
Dolomite & & & & & \\
\hline
\end{tabular}

Table 2. Fitting parameters for (GA-MD t) model

\begin{tabular}{|c|c|c|c|c|c|}
\hline \multirow{2}{*}{$\begin{array}{l}\text { Aggregate } \\
\text { Type }\end{array}$} & \multicolumn{3}{|c|}{ Angularity Model Fitting Parameters } & \multirow[t]{2}{*}{ SSE } & \multirow[t]{2}{*}{$R^{2}$} \\
\hline & $a_{G A}$ & $b_{G A}$ & $c_{G A}$ & & \\
\hline $\begin{array}{l}\text { Calcined } \\
\text { Bauxite (CB) }\end{array}$ & 2048.391 & 741.009 & $1.39 \mathrm{E}-02$ & $2.71 \mathrm{E}-23$ & 1.00 \\
\hline $\begin{array}{l}\text { Meramec } \\
\text { River Agg. }\end{array}$ & 2797.824 & -48.224 & $-7.39 \mathrm{E}-03$ & $3.54 \mathrm{E}-23$ & 1.00 \\
\hline Flint Chat & 3073.900 & -74.200 & $1.68 \mathrm{E}+09$ & $3.38 \mathrm{E}+03$ & 0.52 \\
\hline Earthwork & 2840.295 & 597.005 & $2.84 \mathrm{E}-02$ & $5.20 \mathrm{E}-17$ & 1.00 \\
\hline Rhyolite & 3465.189 & -144.389 & $-6.43 \mathrm{E}-03$ & $2.50 \mathrm{E}-22$ & 1.00 \\
\hline Steel Slag & 3467.057 & -3.257 & $-2.02 \mathrm{E}-02$ & $7.96 \mathrm{E}-22$ & 1.00 \\
\hline $\begin{array}{l}\text { Potosi } \\
\text { Dolomite }\end{array}$ & 1836.972 & 921.728 & $2.05 \mathrm{E}-02$ & $6.00 \mathrm{E}-24$ & 1.00 \\
\hline
\end{tabular}

Table 3. Fitting parameters for (SP-MD t) model

\begin{tabular}{|c|c|c|c|c|c|}
\hline \multirow{2}{*}{$\begin{array}{l}\text { Aggregate } \\
\text { Type }\end{array}$} & \multicolumn{3}{|c|}{ Sphericity Model Fitting Parameters } & \multirow[t]{2}{*}{$S S E$} & \multirow[t]{2}{*}{$R^{2}$} \\
\hline & $a_{S P}$ & $b_{S P}$ & $c_{S P}$ & & \\
\hline $\begin{array}{l}\text { Calcined } \\
\text { Bauxite (CB) }\end{array}$ & 0.558 & $1.00 \mathrm{E}-02$ & $3.40 \mathrm{E}-01$ & $8.00 \mathrm{E}-06$ & 0.89 \\
\hline $\begin{array}{l}\text { Meramec } \\
\text { River Agg. }\end{array}$ & 0.577 & $-6.50 \mathrm{E}-03$ & $4.25 \mathrm{E}-01$ & $4.05 \mathrm{E}-05$ & 0.41 \\
\hline Flint Chat & 0.593 & $-6.00 \mathrm{E}-03$ & $2.01 \mathrm{E}-01$ & $1.80 \mathrm{E}-05$ & 0.57 \\
\hline Earthwork & 0.665 & $-1.78 \mathrm{E}-02$ & $3.93 \mathrm{E}-03$ & $1.02 \mathrm{E}-19$ & 1.00 \\
\hline Rhyolite & 0.612 & $1.32 \mathrm{E}-02$ & $2.27 \mathrm{E}-02$ & $4.42 \mathrm{E}-22$ & 1.00 \\
\hline Steel Slag & 0.575 & $-9.46 \mathrm{E}-04$ & $-1.36 \mathrm{E}-02$ & $4.61 \mathrm{E}-24$ & 1.00 \\
\hline $\begin{array}{l}\text { Potosi } \\
\text { Dolomite }\end{array}$ & 0.585 & $1.45 \mathrm{E}-02$ & $2.42 \mathrm{E}-01$ & $1.25 \mathrm{E}-05$ & 0.92 \\
\hline
\end{tabular}
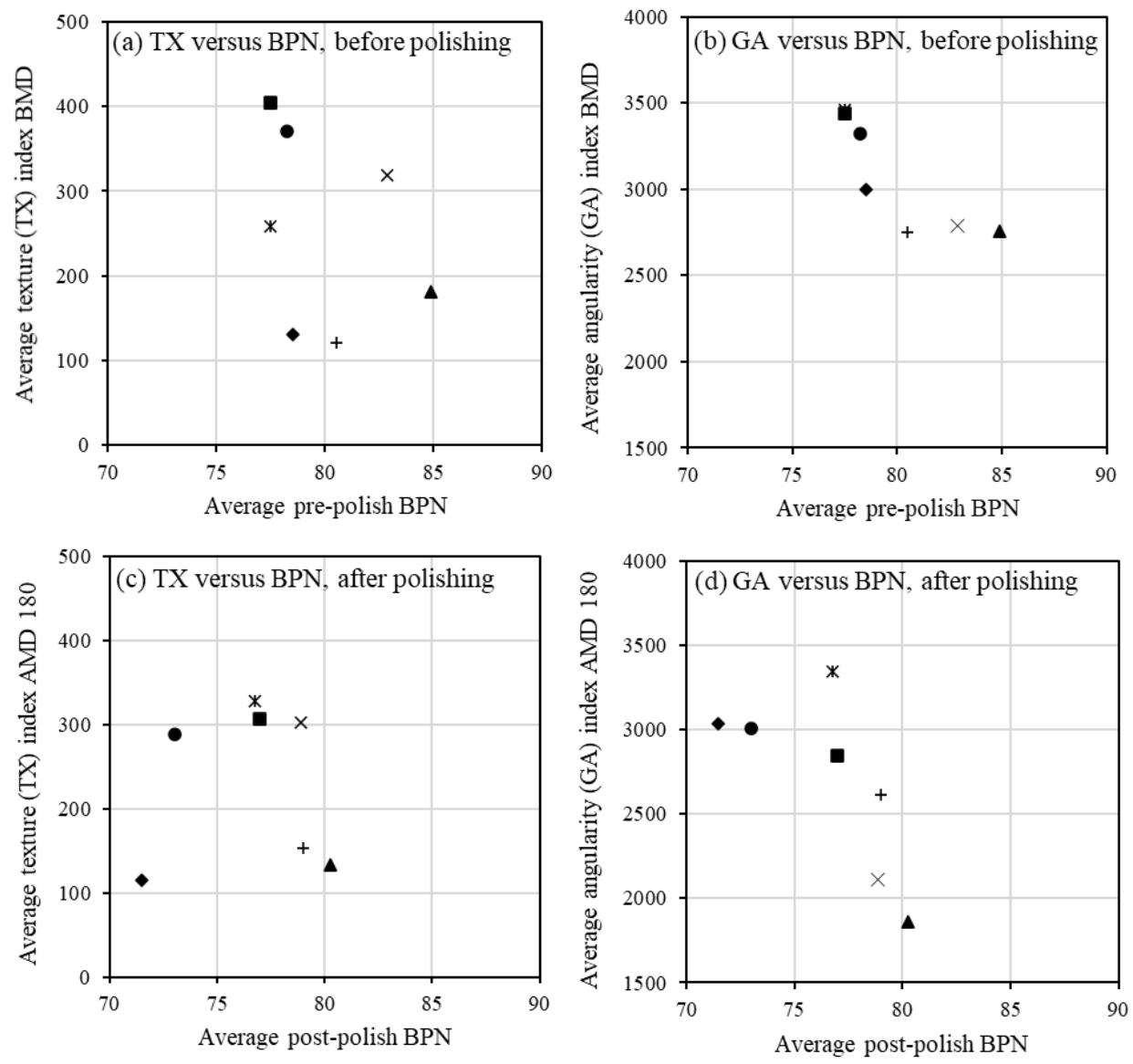

$\boldsymbol{X}$ Calcined Bauxite $\boldsymbol{\Delta}$ Potosi Dol omite $\boldsymbol{\square}$ Earthworks $\bullet$ Flint Chat + Meramec River Agg. $\bullet$ Rhyolite $\boldsymbol{*}$ Steel Slag

Figure 9. Correlations between AIMS and BPT results 


\section{Correlations between AIMS and DFT Results}

Average AIMS texture and angularity indices for $3 / 8^{\prime \prime}$ $1 / 4 "$ and 1/4" - \#4 aggregate sizes were compared with the average COF values measured by DFT at $40 \mathrm{~km} / \mathrm{hr}\left(\mathrm{DFT}_{40}\right)$ for \#6 - \#8 aggregate size. Fig. 10 exhibits average $\mathrm{DFT}_{40}$ and AIMS results for aggregates. Average initial $\mathrm{DFT}_{40}$ were compared with average AIMS texture and angularity indices BMD (see Fig. 9a and Fig. 9b). Average terminal DFT 40 were compared with average AIMS texture and angularity indices for AMD 180 (see Fig. 9c and Fig. 9d). There were no correlations between AIMS and DFT results. Calcined Bauxite had the highest initial and terminal $\mathrm{DFT}_{40}$; however, it yielded the lowest angularity indices for BMD and AMD 180. Steel Slag resulted in the lowest initial $\mathrm{DFT}_{40}$ after Meramec River Aggregate; however, it had the highest AIMS angularity indices for BMD and AMD 180. Earthworks had the lowest terminal $\mathrm{DFT}_{40}$; however, it had the second-highest AIMS texture index for AMD 180.

\section{E. Correlations between BP and DFT Results}

Correlations between $\mathrm{DFT}_{40}$ and BPN values are shown in Fig. 11; they include aggregates with \#6 - \#8 size before polishing and after polishing (BP and AP). The outliers were
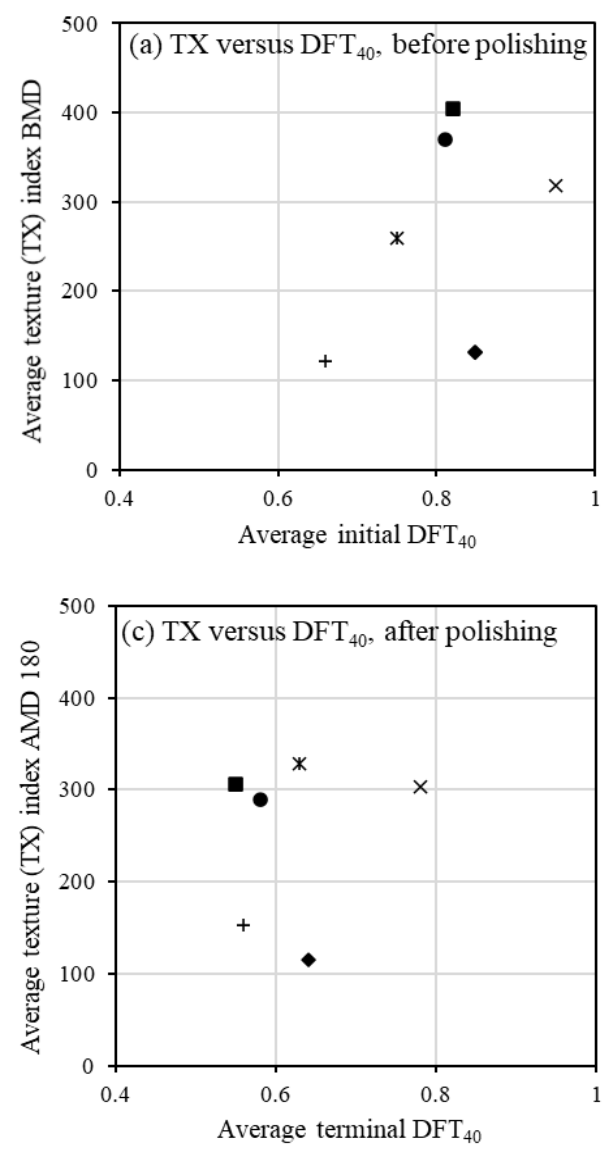

removed from the trendlines; these outliers were indicated with a light gray color. A direct linear correlation was observed, as shown in this figure. Aggregates with high $\mathrm{DFT}_{40}$ showed high BPN values. Before the polishing process, by the TWPD or the British wheel, aggregates presented the highest $\mathrm{DFT}_{40}$ and the BPN results. By contrast, after polishing, the $\mathrm{DFT}_{40}$ and the BPN values decreased. Calcined Bauxite had the highest $\mathrm{DFT}_{40}$ and the highest BPN values before and after polishing. Steel Slag had the lowest $\mathrm{DFT}_{40}$ and the lowest BPN values BP; however, Rhyolite had the lowest $\mathrm{DFT}_{40}$ and BPN values AP.

A prediction model-correlated $\mathrm{DFT}_{40}$ and $\mathrm{BPN}$ results - was evaluated based on the correlations in Fig. 11, as is presented in Eq. (9). The predicted versus the measured BPN values are displayed in Fig. 12.

$B P N=a \times D F T_{40}+b$

where $B P N$ is the British pendulum number value, $D F T_{40}$ is the COF measured by the dynamic friction tester at 40 $\mathrm{km} / \mathrm{hr}$, and $a$ and $b$ are the fitting parameters ( $a=29.458$ and $b=53.71)$.
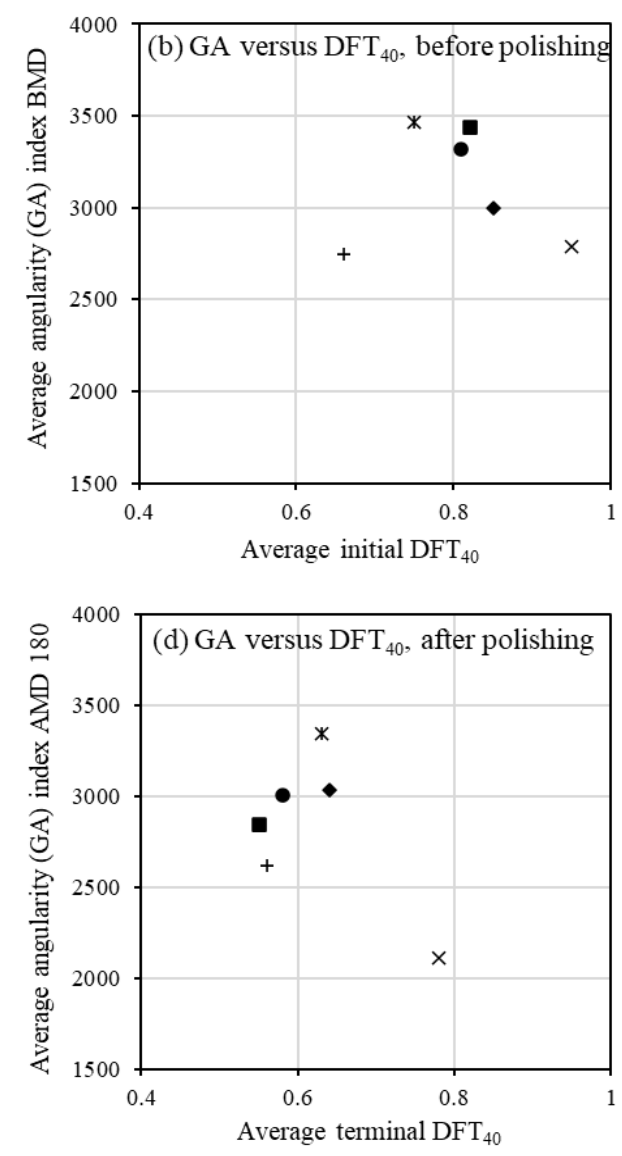

$\times$ Calcined Bauxite $\bullet$ Flint Chat $\mathbf{\square}$ Earthworks $\bullet$ Rhyolite $\boldsymbol{*}$ Steel Slag + Meramec River Agg.

Figure 10. Correlations between AIMS and DFT results 

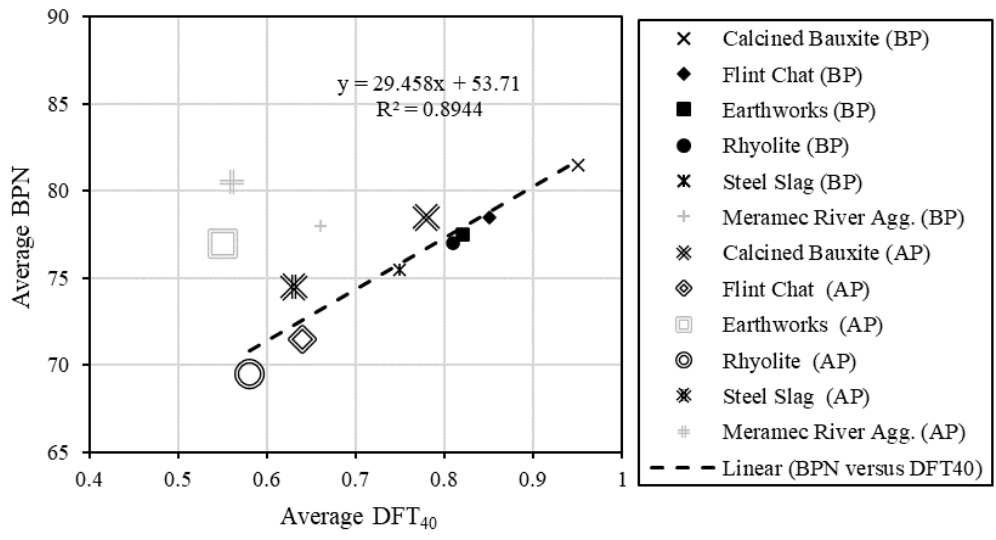

Figure 11. Correlations between BPT and DFT results

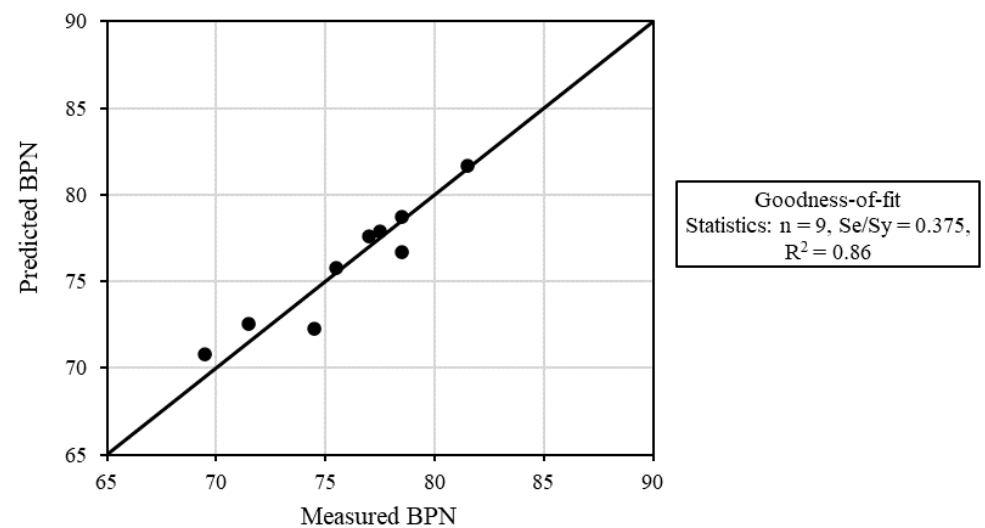

Figure 12. Predicted versus measured BPN values

\section{CONCLUSIONS}

The frictional performance correlations for Calcined Bauxite and six alternatives were explored in this paper. The alternatives were Meramec River Aggregate, Flint Chat, Earthworks, Rhyolite, Steel Slag, and Potosi Dolomite. The frictional performance testing included aggregate image measurement system (AIMS), British pendulum (BP), and dynamic friction. Furthermore, the Micro-Deval (MD) test was utilized, and its results were correlated with the frictional performance results. The AIMS testing evaluated the aggregates' shapes by measuring texture, angularity, and sphericity indices before and after MD 105- and 180-minutes abrasion times. The British pendulum numbers were measured for the aggregates before and after polishing by the British wheel. The coefficients of friction were assessed using the dynamic friction tester (DFT) at $40 \mathrm{~km} / \mathrm{hr}$ speed before and after polishing using the three-wheel polishing machine. Based on this study, the following conclusions were drawn:

- Direct linear correlations were detected between texture and angularity indices.

- Exponential correlations were noted between texture and sphericity indices and between angularity and sphericity indices.

- A stronger correlation was observed between angularity and sphericity indices when compared with the correlation between the texture and sphericity indices or with the correlation between texture and angularity indices.
- Inverse correlations were found between the percentages of mass losses and texture or angularity indices.

- Exponential correlations were remarked between Micro-Deval abrasion times and texture, angularity, or sphericity indices.

- No correlations were discerned between AIMS and BP results or between AIMS and DFT results.

- A direct linear correlation was found between DFT and BP results.

\section{ACKNOWLEDGMENT}

The authors appreciate Missouri Department of Transportation (MoDOT) for providing them with the fund, instruments, and information for this study. This work was funded by MoDOT (project No. TR202005).

\section{REFERENCES}

[1] FHWA, 2020, High friction surface treatment (HFST) quick reference, [online] Available:

https://www.fhwa.dot.gov/publications/research/safety/highfriction/Hi gh-Friction-Surface-Treatment-final.pdf. [accessed 3 March 2021].

[2] D. Merritt, M. Moravec, and M. Heitzman, 2014, High friction surface treatment aggregate durability study, [online] Available: https://vtechworks.lib.vt.edu/bitstream/handle/10919/54620/Merritt.pd f? sequence $=1$ \&isAllowed=y. [accessed 9 March 2021].

[3] R. Milstead, X. Qin, B. Katz, J. Bonneson, M. Pratt, J. Miles, and P. Carlson, Procedures for setting advisory speeds on curves, Final report: FHWA-SA-11-22, Federal Highway Administration, Office of Safety, Washington, D.C., U.S.A. June 2011.

[4] B. Wilson and A. Mukhopadhyay, Alternative aggregates and materials for high friction surface treatments, Final report: Project BDR74-977-05, Texas A\&M Transportation Institute, College Station, Texas, U.S.A., May 2016. 
[5] D. L. Bloem, Skid Resistance: The role of aggregates and other factors, in: National Sand and Gravel Association Circular 109, Silver Spring, MD, U.S.A. 1971

[6] FHWA-CAI-14-019, Frequently asked questions about high friction surface treatments (HFST), [online] Available: https://www.fhwa.dot.gov/innovation/everydaycounts/edc-2/pdfs/fhwa -cai-14-019_faqs_hfst_mar2014_508.pdf. [accessed 9 March 2021].

[7] E. Deef-Allah, K. Broaddus, and M. Abdelrahman, Evaluation of alternatives to calcined bauxite for use in high friction surface treatment (HFST) in Missouri, Final report: cmr21-006, Missouri Department of Transportation, Jefferson City, MO, U.S.A., September 2021.

[8] E. Deef-Allah, K. Broaddus, and M. Abdelrahman, Life cycle cost analysis of high friction surface treatment applications, in: $101^{\text {st }}$ TRB Annual Meeting, Washington, D.C., U.S.A., January 2022.

[9] M. Heitzman, P. Turner, and M. Greer, High friction surface treatment alternative aggregates study, Final report: NCAT Report No. 15-04, Federal Highway Administration, Washington, D.C., U.S.A., July 2015.

[10] M. Heitzman and J. Moore, Evaluation of laboratory friction performance of aggregates for high friction surface treatments, Final report: NCAT Report 17-01, National Center for Asphalt Technology at Auburn University, Auburn, AL, U.S.A., January 2017.

[11] E. Kassem, A. Awed, E. A. Masad, and D. N. Little, Development of predictive model for skid loss of asphalt pavements, Transp. Res. Rec. 2372(1): 83-96, January 2013, doi:10.3141/2372-10.

[12] E. M. Mahmoud, Development of experimental methods for the evaluation of aggregate resistance to polishing, abrasion, and breakage, M.Sc. Thesis, Texas A\&M University, College Station, TX, U.S.A., 2005.

[13] S. Aldagari, M. Al-Assi, E. Kassem, A. Chowdhury, and E. Masad, Development of predictive models for skid resistance of asphalt pavements and seal coat, Int. J. Pavement Eng.: 1-13, May 2020, doi:10.1080/10298436.2020.1766685.

[14] M. Greer, Evaluation of the AIMS-II and Micro-Deval for friction characteristics of aggregates, M.Sc. Thesis, Auburn University, Auburn, Alabama, U.S.A., 2015.

[15] S. Li, R. Xiong, D. Yu, G. Zhao, P. Cong, and Y. Jiang, Friction Surface Treatment Selection: Aggregate properties, surface characteristics, alternative treatments, and safety effects, Final report: FHWA/IN/JTRP-2017/09, Indiana Department of Transportation, Indianapolis, IN, U.S.A. July 2017.

[16] ASTM D6928-17, Standard test method for resistance of coarse aggregate to degradation by abrasion in the Micro-Deval apparatus, ASTM International, West Conshohocken, PA, U.S.A., 2017, doi:10.1520/D6928-17.

[17] E. Masad, A. Rezaei, and A. Chowdhury, Field evaluation of asphalt mixture skid resistance and its relationship to aggregate characteristics, Final report: FHWA/TX-11/0-5627-3, Texas Department of Transportation, Austin, TX, U.S.A., August 2011.

[18] ASTM E1911-19, Standard test method for measuring surface frictional properties using the dynamic friction tester, ASTM International, West Conshohocken, PA, U.S.A., 2019, doi:10.1520/E1911-19.

[19] AASHTO T 278-90 (2017), Standard method of test for surface frictional properties using the British pendulum tester, AASHTO provisional standards, Washington, D.C., U.S.A., 2017.

[20] AASHTO T 279-18, Standard method of test for accelerated polishing of aggregates using the British wheel, AASHTO provisional standards, Washington, D.C., U.S.A., 2018. 